\title{
Corrosion Characteristics of As-Cast Aluminium Bronze Alloy in Selected Aggressive Media
}

\author{
Bukola Joseph Babalola, ${ }^{1,2}$, Michael Oluwatosin Bodunrin ${ }^{3}$, Joseph Olatunde Borode ${ }^{3}$, \\ Kenneth Kanayo Alaneme ${ }^{3}$ \\ ${ }^{1}$ Prototype Engineering Development Institute, Ilesa, Nigeria \\ ${ }^{2}$ National Agency for Science and Engineering Infrastructure (NASENI), Abuja, Nigeria \\ ${ }^{3}$ Metallurgical \& Materials Engineering Department, Federal University of Technology, Akure, Nigeria \\ Email: joseph_babs@yahoo.com
}

Received June 4, 2013; revised July 8, 2013; accepted July 18, 2013

Copyright (C) 2013 Bukola Joseph Babalola et al. This is an open access article distributed under the Creative Commons Attribution License, which permits unrestricted use, distribution, and reproduction in any medium, provided the original work is properly cited.

\begin{abstract}
This research work investigated the corrosion characteristics of aluminium bronze alloy in four selected aggressive media which are $\mathrm{H}_{2} \mathrm{SO}_{4}, \mathrm{HCl}, \mathrm{NaOH}$, and $\mathrm{NaCl}$. Aluminium bronze alloy was produced locally via sand casting method. Copper coils and aluminium materials which constitute waste to the environment were used in producing the alloy. Test specimens were produced from the as cast alloy and immersed in $\mathrm{H}_{2} \mathrm{SO}_{4}, \mathrm{HCl}, \mathrm{NaOH}$, and $\mathrm{NaCl}$ environment. The concentrations of the environment were varied as $0.1 \mathrm{M}, 0.3 \mathrm{M}$ and $0.5 \mathrm{M}$. The aluminium bronze produced from sand casting has mechanical properties that are closer to the standards proposed by CDA [1]. The corrosion rate was determined by weight loss method at an interval of 3 days. It was observed that the corrosion behaviour exhibited by aluminium bronze in acidic media followed similar trends in $0.1 \mathrm{M}, 0.3 \mathrm{M}$ and $0.5 \mathrm{M}$ respectively. However, the corrosion rates increases with increase in the concentration of $\mathrm{H}_{2} \mathrm{SO}_{4}$ and $\mathrm{NaCl}$ media, but the attack was more aggressive in $\mathrm{HCl}$ medium. The aluminium bronze samples in $\mathrm{NaOH}$ and $\mathrm{H}_{2} \mathrm{SO}_{4}$ media show gradual decolouration from its as-cast yellow golden colour to brown and dark colour respectively. $\mathrm{NaCl}$ environment shows high resistance to corrosion and slight decolouration effect even at increased concentration.
\end{abstract}

Keywords: Corrosion; Aluminium Bronze; Aggressive Media; Sand Casting; Aluminium

\section{Introduction}

Aluminium bronze is a material that has been established to have excellent corrosion properties. They are range of copper based alloys in which aluminium ranging to $14 \%$ is the primary alloying element [2]. Aluminium bronzes are finding increasing application in chemical, petrochemical, desalination plant, marine, power generation, aircraft, automotive, iron and steel making, electrical and building industries. Foundry products achievable from the alloy are impellers, propellers, shafts, pumps and valves, water cooled compressors, non-sparking tools just to mention a few. Aluminium bronze castings are produced by recognized sand, shell, die, ceramic, investment and centrifugal casting [1,3]. Aluminium bronze is a material found to exhibit a short cooling range characteristic [1], therefore its feasibility of production via sand casting technique locally and its corrosion behavior compared to conventionally produced aluminium bronze alloys need to be investigated. One of the conventional ways of pro- ducing this alloy has been via centrifugal casting [4]. This research work has investigated the corrosion of aluminium bronze alloy produced via sand casting technique in $\mathrm{H}_{2} \mathrm{SO}_{4}, \mathrm{HCl}, \mathrm{NaOH}$, and $\mathrm{NaCl}$ environment. Sand casting technique in the production of aluminium bronze alloy is more economical and an easier route for the production of aluminium bronze alloy in developing country like Nigeria where there are limited access to facilities. Improper disposed copper coils which constitute solid waste to the environment were used in the production of this alloy. This is in a bid to convert waste to useful material.

\section{Materials and Method}

\subsection{Materials}

The material used for this study was dual phase aluminium bronze produced locally via sand casting method. The charge calculation was carried out to determine the amount of charged materials to produce aluminium bronze alloy having up to $11 \%$ aluminium by mass. The 
chemical composition of the alloy produced is as shown in Table 1 below.

\subsection{Methods}

\section{Melting and Casting}

Charge calculation was carried out to determine the quantity of charge needed to produce the desired aluminium bronze alloy. Thereafter, melting operation was carried out on the charge in a pit furnace as shown in Figure 1. Casting process of this alloy started with the melt of pieces of copper coils and aluminium. The temperature of the molten metal was $1300^{\circ} \mathrm{C}$. The molten metal was poured quickly to prevent the molten metal from solidifying due to short freezing range of the metal. The density of the cast alloy was calculated by measuring the mass, area, volume of ten (10) test specimens, the density of each was calculated from first principle as shown in Equation (1):

$$
\text { Density }=\frac{\text { Mass }}{\text { Volume }}
$$

Table 1. Chemical composition of dual phase aluminium bronze alloy produced.

\begin{tabular}{cccccccc}
\hline Element & $\mathrm{Cu}$ & $\mathrm{Al}$ & $\mathrm{Zn}$ & $\mathrm{Mn}$ & $\mathrm{Fe}$ & $\mathrm{Si}$ & $\mathrm{Mg}$ \\
\hline Percent & Others & 10.837 & 0.5 & 1 & 0.0242 & 0.0495 & 0.055 \\
\hline
\end{tabular}

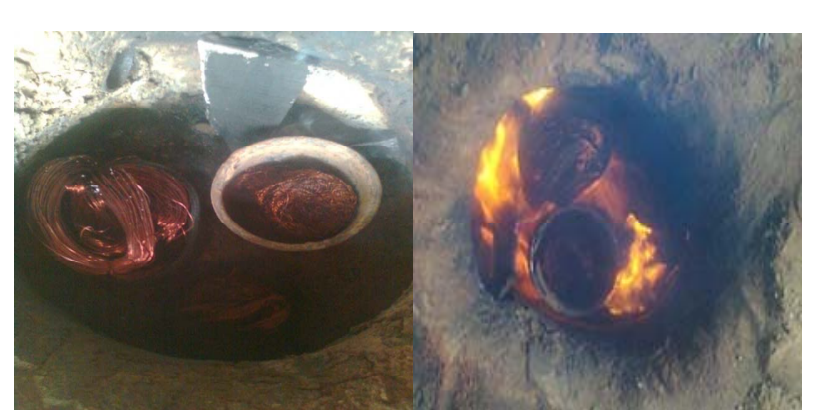

(a)

(b)

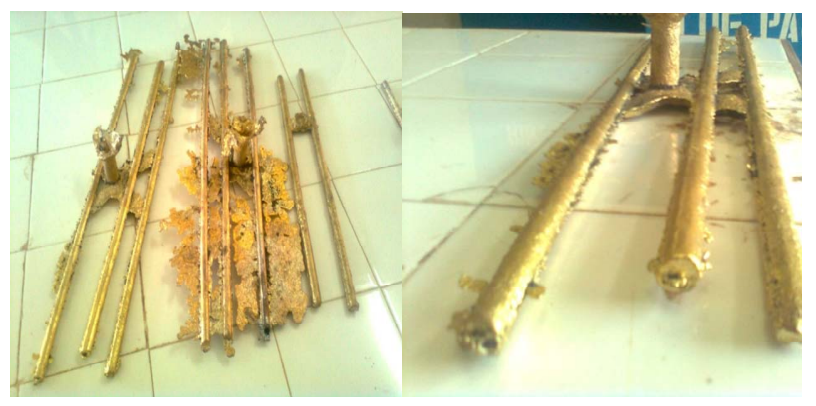

(c)

(d)

Figure 1. Charging and cast produced. (a) Charging of copper coils into the pit furnace contained in two crucibles; (b) Ignition of the furnace; (c), (d) aluminium bronze rod cast from the melt. Figures 1(a)-(d) illustrate the production process of aluminium bronze. Pit furnace was used to achieve the melt of charged alloy constituents.
The average density of the alloy was calculated adding the densities divided by number of test specimen evaluated.

\section{Mechanical Test}

This process includes the following tests which are hardness test using Digital Rockwell testing machine, tensile test using Instron Universal Testing machine operated at a constant cross head speed of $1 \mathrm{~mm} / \mathrm{s}$ in accordance with ASTM E8M-11 standard [5].

\section{Preparation of Specimen (surface)}

The dual phase aluminium bronze samples were machined and cut into test specimens of $10 \mathrm{~mm}$ diameter, and $20 \mathrm{~mm}$ length. The samples surfaces were treated by abrading them through successive grades of silicon carbide papers of grades P60, P120, P320, P400 and P600 grit, and finally on the emery cloth. They were rinsed in distilled water and then in acetone before drying. The prepared samples were stored in desiccators until the start of the experiment.

\section{Preparation of Aggressive Environments}

The environments prepared for the evaluation of its corrosion behaviour were $\mathrm{HCl}, \mathrm{H}_{2} \mathrm{SO}_{4}$, simulated sea water, and $\mathrm{NaOH}$ media solutions. Each of the environments ranges from a concentration of $0.1 \mathrm{M}, 0.3 \mathrm{M}$, and $0.5 \mathrm{M}$ which was prepared following standard procedures.

\section{Corrosion Evaluation of Samples}

The aluminium bronze samples were immersed in all prepared environments for duration of 30 days. Electrode potential $(\mathrm{mV})$ measurements between the sample surface and the corrosive environment were carried out at regular interval of $24 \mathrm{hr}$ using a DT8300D digital multimeter with a zinc electrode used as a reference electrode. The reference electrode was not left in the cell for the duration of the experiment but used only at the time of taking measurement and afterwards removed and rinsed. The values obtained from the multimeter were converted to saturated calomel electrode (SCE) values with the use of the formula;

$$
\text { EZN-1030 } \mathrm{mV}=\text { S.C.E values }
$$

The samples were removed from the corrosion environment with the aid of tong, cleaned in distilled water and dried with cotton wool and dried. The dried samples were weighed with digital chemical weighing balance and recorded at an interval of 3 days. Corrosion rate in $\mathrm{mm} / \mathrm{yr}$ were obtained from weight loss analysis using the expression;

$$
C R=\frac{87,500 \mathrm{~W}}{\rho A T}(\mathrm{~mm} / \mathrm{yr})
$$

where $\mathrm{W}$ is the weight loss in mg; $\rho$ is the density of the specimen in $\mathrm{g} / \mathrm{cm}^{3}$; A is the total exposed surface area of the specimen in $\mathrm{cm}^{2}$; and $\mathrm{T}$ is the exposure time in hours; 
$\mathrm{mm} / \mathrm{yr}$ is the corrosion rate expressed in millimetres penetration per year.

\section{Results and Discussions}

\subsection{Casting}

Sand casting was selected as the optimum casting in the country based on its materials availability, low cost and found effective compared to other casting method such as centrifugal casting, die castings among others. The alloy composition was melted using a pit furnace. A sound golden yellow dual-phase aluminium bronze alloy with a density of $7.74 \mathrm{~g} / \mathrm{cm}^{3}$ and composition as shown in Table 1 was produced. Visual examination and density measurement showed that the Aluminium bronze alloy was produced successfully via the sand casting technique despite the fact that Aluminium bronze melt has short freezing range as it transforms rapidly from liquid state to solid state. This freezing range characteristic was reported by Meigh [5].

\subsection{Evaluation of Production Quality}

The quality of the as-cast aluminium bronze alloy produced was evaluated by microstructural analysis as shown in Plate $\mathbf{1}$ and density measurement as shown in Table 2.

\subsection{Mechanical Properties of Aluminium Bronze Alloy Produced}

The results obtained for the as-cast aluminium bronze alloy are presented as shown in Table 2 below which is in close tolerance with data given reported by Copper

Table 2. Showing the mechanical properties of as-cast dual phase aluminium bronze alloy.

\begin{tabular}{|c|c|c|c|}
\hline Treatment & Sample 1 & Sample 2 & $\begin{array}{c}\text { Average of } \\
\text { needed values }\end{array}$ \\
\hline Initial Length, $\mathrm{L}_{\mathrm{o}}(\mathrm{mm})$ & 20 & 20 & \\
\hline Final Length, $\mathrm{L}_{1}(\mathrm{~mm})$ & 22.6 & 27.2 & \\
\hline Initial Area, $\mathrm{A}_{0}\left(\mathrm{~m}^{2}\right)$ & $2.37 \times 10^{-5}$ & $1.964 \times 10^{-5}$ & \\
\hline Strain $\left(\mathrm{L}_{1}-\mathrm{L}_{\mathrm{o}} / \mathrm{L}_{\mathrm{o}}\right)$ & 0.13 & 0.072 & \\
\hline$\%$ Elongation $($ Strain $\times 100)$ & 13.0 & 7.2 & 10.1 \\
\hline $\begin{array}{l}\text { Ultimate Tensile } \\
\text { Force }(\mathrm{KgF})\end{array}$ & 560 & 460 & \\
\hline $\begin{array}{l}\text { Ultimate Tensile Force } \\
\qquad(\mathrm{N}=9.8066 \times \mathrm{KgF})\end{array}$ & 5491.7 & 4511.0 & \\
\hline $\begin{array}{l}\text { Ultimate Tensile Strength } \\
\left(\mathrm{MPa}=\mathrm{UTF} 2 / 10^{6} \mathrm{Ao}\right)\end{array}$ & 231.1 & 229.7 & 230.4 \\
\hline Hardness (HRF) & 78 & 72 & 75 \\
\hline Density $\left(\mathrm{g} / \mathrm{cm}^{3}\right)$ & 7.72 & 7.76 & 7.74 \\
\hline
\end{tabular}

Development Association [4].

\subsection{Corrosion Behavior of Dual Phase Aluminium Bronze Alloy at Media Concentrations of $0.1 \mathrm{M}$}

Figure 2 shows the corrosion rate against exposure time of aluminium bronze samples immersed in $0.1 \mathrm{M}$ of $\mathrm{H}_{2} \mathrm{SO}_{4}, \mathrm{HCl}, \mathrm{NaOH}$, and $\mathrm{NaCl}$ media. It is observed that at media concentration of $0.1 \mathrm{M}$, aluminium bronze alloy was found to have high corrosion rate in $\mathrm{HCl}$ medium compared to other three media. There were colour changes on the surface of the aluminium bronze alloy with respect to each media as shown in Figure 3, except for $\mathrm{HCl}$ medium which exhibited a characteristic green coloured corrosion product. These changes were found to be as a result of dissolution of protecting oxide films on the surface of the alloy [6].

\subsection{Corrosion Behavior of Samples in Media Concentrations of $0.3 \mathrm{M}$}

In Figure 4, the corrosion rate of $\mathrm{HCl}$ medium was observed to be more pronounced due to increased concentration. Samples in the other media were found to have lesser passivation at the early stage compared to the 0.1 $M$ concentration media. And samples in $\mathrm{H}_{2} \mathrm{SO}_{4}, \mathrm{NaOH}$ and simulated sea water were observed to exhibit slight dark colour appearance [7]. The dark colouration increa-

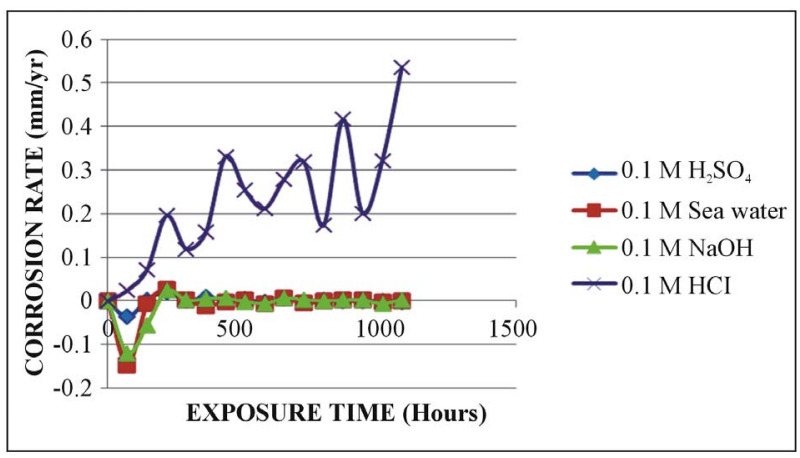

Figure 2. Corrosion of aluminium brone alloy in $0.1 \mathrm{M}$ media.
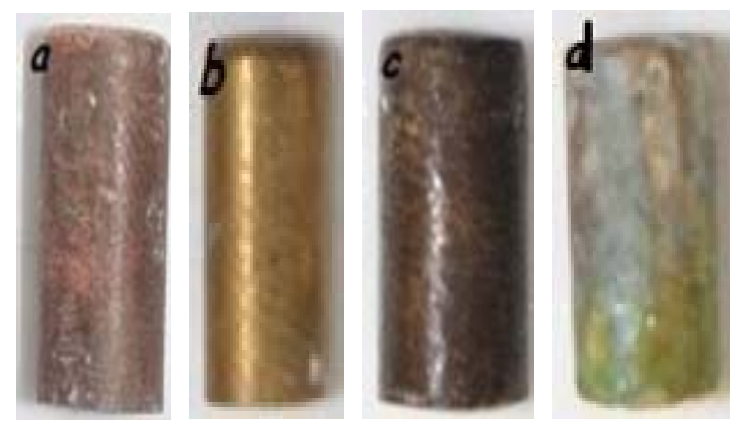

Figure 3. Colour change observed in $0.1 \mathrm{M}$ media. 
ses with increase in concentration of the media as reported by CDA [8] due to protective oxide dissolution, this effect is shown in Figure 5.

\subsection{Corrosion Behavior of Samples in Media Concentrations of $0.5 \mathrm{M}$}

Corrosion of the sample was more pronounced in $\mathrm{HCl}$ medium than in $0.3 \mathrm{M}$ concentration as shown in Figure 6, which was observed to be the dealloying of the aluminium phase. This effect is known as dealuminification and was pronounced in the $\mathrm{HCl}$ medium. The samples in $0.5 \mathrm{M} \mathrm{HCl}$ was found to have rough surfaces revealing the dealuminification effect as shown in Figure 7. Also cooling rate from casting, metallurgical structure are likely factors to contribute to the selective dissolution of

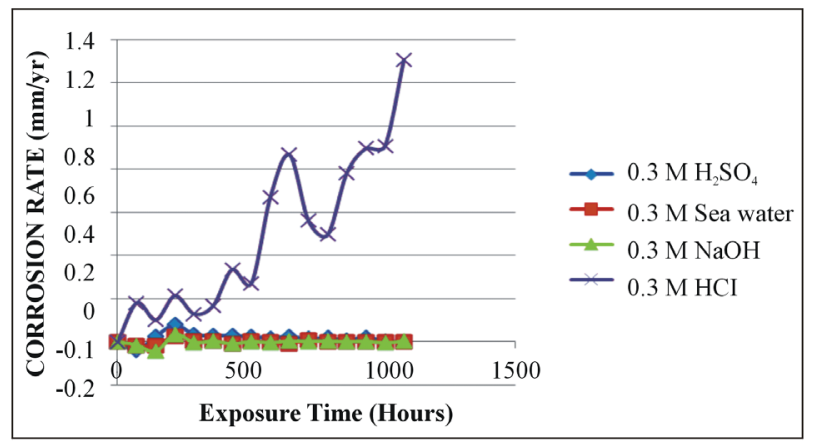

Figure 4. Corrosion of aluminium bronze in $0.3 \mathrm{M}$ media.
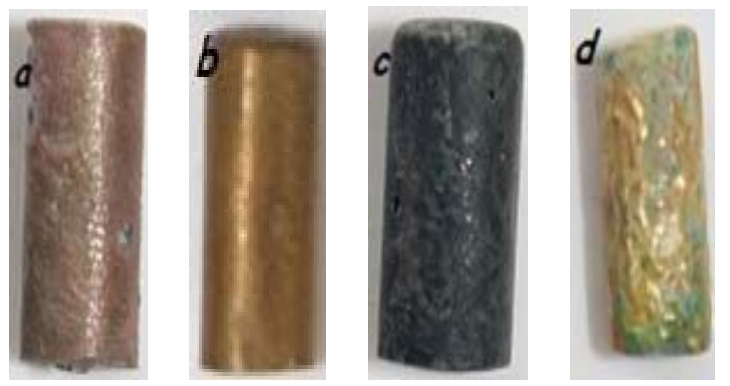

Figure 5. Colour change observed in $0.3 \mathrm{M}$ media.

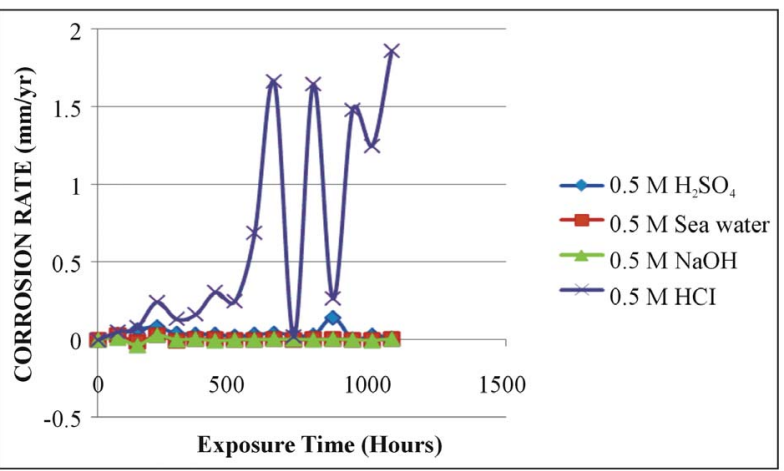

Figure 6. Corrosion of aluminium bronze alloy in $0.5 \mathrm{M}$ media.
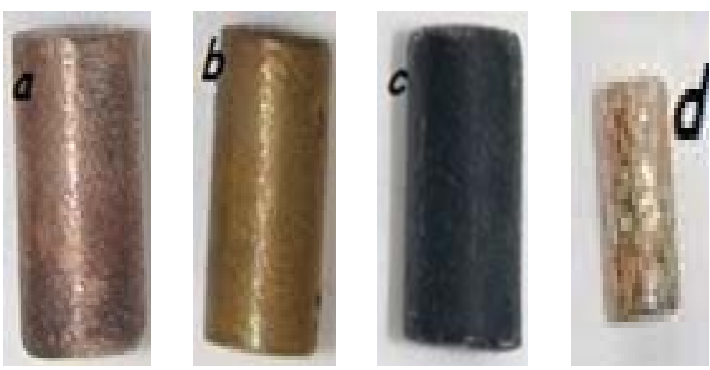

Figure 7. Colour change observed in $0.5 \mathrm{M}$ media.

the principal alloying element which is aluminium [6]. Similar behavior was reported by Campbell in his research work [6]. The curvy nature of the graph represented by $\mathrm{HCl}$ medium indicates the presence of corrosion product acting as a passivate for a short period which draws the graph down. The green-blue coloured corrosion is said to be copper chloride, which is as a result of reaction of cupric oxide and $\mathrm{HCl}$.

However, the alloy was observed to exhibit surface colour changes from its golden appearance to black and brown in $\mathrm{H}_{2} \mathrm{SO}_{4}, \mathrm{NaOH}$ and simulated sea water environment respectively. This is due to the reaction of each environment with protective oxide, aluminium oxide (alumina) present on the alloy. The corrosion product observed in the $\mathrm{HCl}$ media was a characteristic green-blue colored cupper chloride solution which was also affirmed in literatures [3].

\section{Conclusion}

Corrosion characteristic of aluminium bronze alloy produced via sand casting was evaluated in $\mathrm{HCl}, \mathrm{H}_{2} \mathrm{SO}_{4}$, $\mathrm{NaCl}$, and $\mathrm{NaOH}$ with concentrations $0.1 \mathrm{M}, 0.3 \mathrm{M}$ and $0.5 \mathrm{M}$ in each medium. Aluminium bronze was successfully produced via sand casting. The mechanical properties obtained compete favourably with those produced via centrifugal casting in developed countries. The alloy was found to exhibit pronounced corrosion effect in $\mathrm{HCl}$ medium with increase in concentration [9]. The alloy was found to exhibit little corrosion in the $\mathrm{H}_{2} \mathrm{SO}_{4}$ medium even at $0.5 \mathrm{M}$ concentration.

The research work has revealed that the alloy is not suitable for application in aggressive environment such as $\mathrm{HCl}$.

However, the alloy is suitable for service application in $\mathrm{H}_{2} \mathrm{SO}_{4}$ and $\mathrm{NaOH}$ environment taken into consideration that the unique golden colour will not be retained in these environments. $\mathrm{NaCl}$ environment shows high resistance to corrosion and slight decolouration effect even at increased concentration.

\section{REFERENCES}

[1] Copper Development Association, “Aluminium Bronze 
Alloys for Industry," Copper Development Publication, No. 83, 1986, p. 8.

[2] Copper Development Association, "Welding of Aluminium Bronze," Copper Development Association Publication, No. 85, 1988, p. 2.

[3] Gareth Hinds, "The Electrochemistry of Corrosion," Corrosion Doctors Publications, 1996, pp. 4-5.

[4] Copper Development Association, "Aluminium BronzeEssential for Industry," CDA Publication, No. 86, 1989, p. 2.

[5] H. J. Meigh, "Designing Aluminium Bronze Castings," Engineering Technical File No. 116, Copper Development Association, 1983, pp. 5-16.

[6] H. S. Campbell, "Aluminium Bronze Alloys Corrosion Re- sistance Guide," Copper Development Association Publication, No. 80, 1981, pp. 6-22.

[7] C. Powell and H. Stillman, "Corrosion Behaviour of Copper Alloys Used in Marine Aquaculture," International Copper Association, Ltd., New York, 2009, pp. 1-3.

[8] ASTM E8, "Physical Testing Standards and Mechanical Testing Standards," ASTM International, West Conshohocken, 2011. doi:10.1520/E0008_E0008M-11

[9] H. J. Meigh, "Cast and Wrought Aluminium Bronzes: Properties, Processes and Structure," Copper Development Association/IOM Communications, London, 2000, pp. 34. 